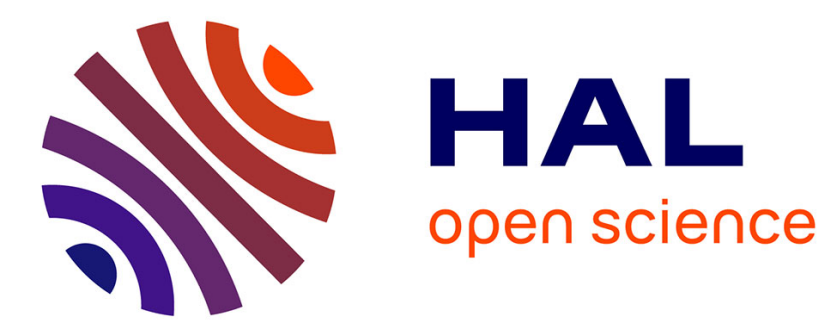

\title{
Analytical calculation of the transient thermoelastic stresses in thick walled composite pipes
}

Frédéric Jacquemin, Alain Vautrin

\section{To cite this version:}

Frédéric Jacquemin, Alain Vautrin. Analytical calculation of the transient thermoelastic stresses in thick walled composite pipes. Journal of Composite Materials, 2004, 38 (19), pp.1733-1751. $10.1177 / 0021998304044766$. hal-01005250

\section{HAL Id: hal-01005250 \\ https://hal.science/hal-01005250}

Submitted on 2 Feb 2017

HAL is a multi-disciplinary open access archive for the deposit and dissemination of scientific research documents, whether they are published or not. The documents may come from teaching and research institutions in France or abroad, or from public or private research centers.
L'archive ouverte pluridisciplinaire HAL, est destinée au dépôt et à la diffusion de documents scientifiques de niveau recherche, publiés ou non, émanant des établissements d'enseignement et de recherche français ou étrangers, des laboratoires publics ou privés. 


\title{
Analytical Calculation of the Transient Thermoelastic Stresses in Thick Walled Composite Pipes
}

\author{
F. JACQUEMIN ${ }^{1}$ AND A. VAUTRIN ${ }^{2}$ \\ ${ }^{\text {I}}$ Laboratoire d'Applications des Matériaux à la Mécanique \\ Université de Nantes, boulevard de l'Université \\ BP 406, 44602 Saint Nazaire cedex, France \\ ${ }^{2}$ Département Mécanique et Matériaux \\ École Nationale Supérieure des Mines de Saint Étienne \\ 158 cours Fauriel, 42023 Saint Étienne cedex 2, France
}

\begin{abstract}
This article aims at assessing the internal stresses in thick laminated pipes, composed of orthotropic plies, subjected to transient thermal fields. The original contribution of the work is to provide novel analytical solutions, based on well founded assumptions, to compute the internal stresses due to transient thermal fields throughout the pipe thickness, within the framework of thermoelasticity. The structures considered here are thick, laminated and anisotropic pipes of infinite length. They are subjected to heat flux conditions on their inner and outer surfaces due to the environmental conditions. The transient thermal field is determined and the thermoelastic stresses are derived by using the classical equations of solid mechanics and assuming a thermoelastic orthotropic ply behavior. Finally, particular attention is paid to wall thickness effect.
\end{abstract}

KEY WORDS: thermoelastic stresses, transient, thick pipe, laminate, anisotropy.

\section{INTRODUCTION}

$\mathbf{T}$

HE DETERMINATION OF internal stress fields in thick walled composite laminated cylinders is a key issue to optimize industrial pipes, especially when those pipes are subjected to time dependent hygrothermal loading. Such a calculation provides more accurate information on the structural behavior at any time. Finally, it supplies rational bases to set up more effective life time prediction methodology. In the literature, different analytical calculations can still be found to determine thermoelastic stresses within laminated pipes. 
However, such analytical solutions have been derived under quite restrictive assumptions on thermal loading and mechanical fields. For instance, Hyer and Rousseau [1] and Shin and Sekine [2] published analytical approaches to compute thermoelastic stresses due to time and space independent temperature fields within thick walled laminated pipes. Timoschenko and Goodier [3] considered both time and space dependent temperature fields but computed stresses in the very special case of isotropic cylinders. Ootao et al. [4] and Tanigawa et al. [5] considered time dependent temperature fields for composite laminated hollow cylinders composed of isotropic plies only. Therefore, at present, there is no analytical solution to tackle problems involving thick laminated hollow cylinders, composed of orthotropic plies, under time dependent temperature changes. Since such varying boundary conditions are quite usual in industrial applications, well-controlled solutions simulating transient evolutions are obviously of high practical importance.

In the present article we establish a reference solution which allows to compute thermoelastic stresses due to transient thermal fields through thick laminated tube-like composite structures. To get rid of the usual restrictive assumptions met in the literature, we first determine the transient thermal field throughout the thickness and then solve the usual set of equations of 3D solid mechanics for every ply at any time: constitutive laws of thermoelastic orthotropic materials, strain-displacement relations, compatibility and equilibrium equations and boundary conditions. The use of the Tsai $\mathrm{Wu}$ strength criterion allows us to estimate the internal stresses versus the ply strength in case of heating or cooling processes. The effect of wall thickness on the internal stress state is investigated.

\section{DEFINITION OF THE PROBLEM}

We consider a pipe (Figure 1), made up of $n$ perfectly bonded plies, whose inner and outer radii are $a$ and $b$ respectively. Any ply $i$ of the pipe is a cylinder whose inner and outer radii are $r_{i}$ and $r_{i+1}$ respectively. It contains an internal fluid and is surrounded by an external one, both fluids being initially at the same uniform temperature $T_{0}$. The fluids are then assumed to be instantly heated at the constant temperatures $T_{\text {int }}$ and $T_{\text {ext }}$. Thermal transfers between the fluids and the pipe are controlled by heat transfer coefficients

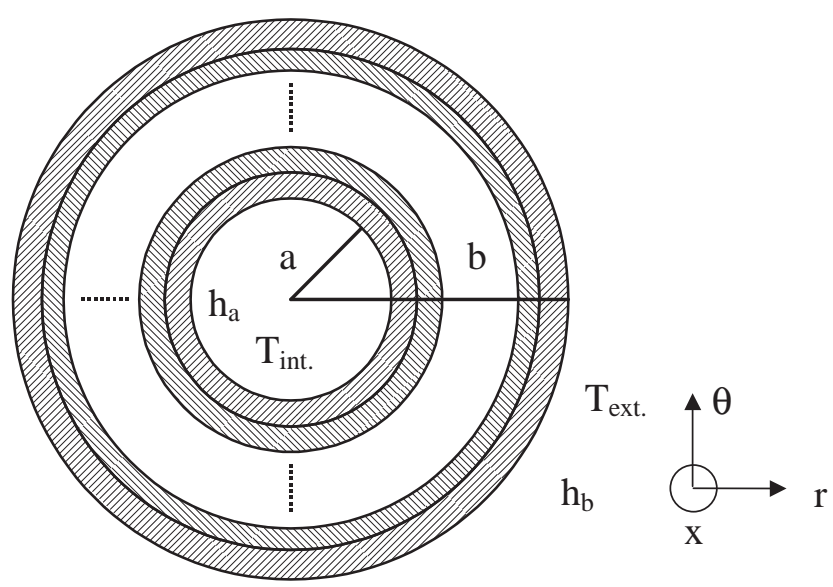

Figure 1. Hollow laminated cylinder subjected to heat transfers on external surfaces. 
$h_{a}$ and $h_{b}$, which are kept constant. Conditions of continuity of the temperature and heat flux are prescribed at any ply interface. $k_{i}$ is the through-thickness thermal diffusivity of ply $i$.

The temperature field in ply $i$ is the solution of the following system (1)-(2):

$$
\begin{aligned}
\frac{\partial T_{i}}{\partial t}= & k_{i}\left(\frac{\partial^{2} T_{i}}{\partial r^{2}}+\frac{1}{r} \frac{\partial T_{i}}{\partial r}\right) \quad a<r<b, i=1 \text { to } n \\
& \left\{\begin{array}{l}
T_{i}\left(r_{i}, t\right)=T_{i+1}\left(r_{i}, t\right) \\
\lambda_{i} \frac{\partial T_{i}\left(r_{i}, t\right)}{\partial r}=\lambda_{i+1} \frac{\partial T_{i+1}\left(r_{i}, t\right)}{\partial r} \\
\frac{\partial T_{1}(a, t)}{\partial r}-h_{a}\left(T_{1}(a, t)-T_{\mathrm{int}}\right)=0 \\
\frac{\partial T_{n}(b, t)}{\partial r}-h_{b}\left(T_{\mathrm{ext}}-T_{n}(b, t)\right)=0 \\
T_{i}(r, 0)=T_{0}
\end{array}\right.
\end{aligned}
$$

We introduce the following dimensionless parameters:

$$
\begin{aligned}
\bar{T}_{i} & =\frac{\left(T_{i}-T_{0}\right)}{\left(T_{\mathrm{int}}-T_{0}\right)}, \\
\bar{k}_{i} & =\bar{\lambda}_{i} /\left(\bar{c}_{i} \bar{\rho}_{i}\right), \quad \bar{\lambda}_{i}=\lambda_{i} / \lambda_{0}, \\
\bar{c}_{i} & =c_{i} / c_{0}, \quad \bar{\rho}_{i}=\rho_{i} / \rho_{0}, \quad(\bar{r}, \bar{a})=(r, a) / b, \\
\tau & =\lambda_{0} t /\left(c_{0} \rho_{0} b^{2}\right), \quad H_{a}=b h_{a}, \quad H_{b}=b h_{b},
\end{aligned}
$$

where, $T_{i}, \lambda_{i}, c_{i}$ and $\rho_{i}$ are, respectively, the temperature, the transverse thermal conductivity, the specific heat and the density of the ply $i$. The typical values of temperature, thermal conductivity, specific heat and density are respectively $T_{0}, \lambda_{0}, c_{0}$ and $\rho_{0}$.

The system (1)-(2) writes in a dimensionless form:

$$
\begin{aligned}
\frac{\partial \bar{T}_{i}}{\partial \tau}=\bar{k}_{i}\left(\frac{\partial^{2} \bar{T}_{i}}{\partial \bar{r}^{2}}+\frac{1}{\bar{r}} \frac{\partial \bar{T}_{i}}{\partial \bar{r}}\right) \frac{a}{b}<\bar{r}<1, \quad i=1 \text { to } n \\
\\
\left\{\begin{array}{l}
\bar{T}_{i}\left(\bar{r}_{i}, \tau\right)=\bar{T}_{i+1}\left(\bar{r}_{i}, \tau\right) \\
\bar{\lambda}_{i} \frac{\partial \bar{T}_{i}\left(\bar{r}_{i}, \tau\right)}{\partial \bar{r}}=\bar{\lambda}_{i+1} \frac{\partial \bar{T}_{i+1}\left(\bar{r}_{i}, \tau\right)}{\partial \bar{r}} \\
\frac{\partial \bar{T}_{1}(\bar{a}, \tau)}{\partial \bar{r}}-H_{a}\left(\bar{T}_{1}(\bar{a}, \tau)-1\right)=0 \\
\frac{\partial \bar{T}_{n}(1, \tau)}{\partial \bar{r}}-H_{b}\left(\bar{T}_{\mathrm{ext}}-\bar{T}_{n}(1, \tau)\right)=0 \\
\bar{T}_{i}(\bar{r}, 0)=0
\end{array}\right.
\end{aligned}
$$


Applying the Laplace transform to system (3)-(4) and by using the residue theory to inverse the solution in the time space [6], we finally obtain the thermal field in every ply $i$ :

$$
\bar{T}_{i}(\bar{r}, \tau)=\frac{1}{\Delta_{s}}\left(A_{i}^{\prime}+B_{i}^{\prime} \ln \bar{r}\right)+\sum_{m=1}^{\infty} \frac{2 \exp \left(-\omega_{m}^{2} \tau\right)}{\omega_{m} \Delta_{u}^{\prime}\left(\omega_{m}\right)}\left\{A_{i} J_{0}\left(\beta_{i} \omega_{m} \bar{r}\right)+B_{i} Y_{0}\left(\beta_{i} \omega_{m} \bar{r}\right)\right\}
$$

where $J_{0}$ and $Y_{0}$ are Bessel's functions of order zero, $\Delta_{u}$ and $\Delta_{s}$ are determinants of $2 n \times 2 n$ matrices $[a]$ and $[b] . A_{i}$ and $B_{i}$ are determinants of matrices deduced from $[a]$ by respectively substituting columns $(2 i-1)$ and $2 i$ by the constant vector $\{g\} . A_{i}^{\prime}$ and $B_{i}^{\prime}$ are similar determinants of $A_{m}$ and $B_{m}$ but with respect to the matrix [b]. $\Delta_{u}^{\prime}\left(\omega_{m}\right)$ is the derivative of $\Delta_{u}$ with respect to $\omega$ calculated for $\omega_{m}$, the $m$ th positive root of $\Delta_{u}$. $\beta_{i}$ is defined by the relation $\beta_{i}=\sqrt{ } 1 / \bar{k}_{i}$.

Furthermore, the non-zero elements of $[a],[b]$ and $\{g\}$ are:

$$
\begin{aligned}
a_{11} & =H_{a} J_{0}\left(\beta_{1} \omega \bar{a}\right)+\beta_{1} \omega J_{1}\left(\beta_{1} \omega \bar{a}\right), \quad a_{12}=H_{a} Y_{0}\left(\beta_{1} \omega \bar{a}\right)+\beta_{1} \omega Y_{1}\left(\beta_{1} \omega \bar{a}\right), \\
a_{2 n 2 n 1} & =H_{b} J_{0}\left(\beta_{n} \omega\right)-\beta_{n} \omega J_{1}\left(\beta_{n} \omega\right), \quad a_{2 n 2 n}=H_{b} Y_{0}\left(\beta_{n} \omega\right)-\beta_{n} \omega Y_{1}\left(\beta_{n} \omega\right), \\
a_{2 i 2 i \quad 1} & =J_{0}\left(\beta_{i} \omega \bar{r}_{i}\right), \quad a_{2 i 2 i}=Y_{0}\left(\beta_{i} \omega \bar{r}_{i}\right), \quad a_{2 i 2 i+1}=-J_{0}\left(\beta_{i+1} \omega \bar{r}_{i}\right), \\
a_{2 i 2 i+2} & =-Y_{0}\left(\beta_{i+1} \omega \bar{r}_{i}\right), \quad a_{2 i+12 i} \quad 1=\bar{\lambda}_{i} \beta_{i} \omega J_{1}\left(\beta_{i} \omega \bar{r}_{i}\right), \quad a_{2 i+12 i}=\bar{\lambda}_{i} \beta_{i} \omega Y_{1}\left(\beta_{i} \omega \bar{r}_{i}\right), \\
a_{2 i+12 i+1} & =-\bar{\lambda}_{i+1} \beta_{i+1} \omega J_{1}\left(\beta_{i+1} \omega \bar{r}_{i}\right), a_{2 i+12 i+2}=-\bar{\lambda}_{i+1} \beta_{i+1} \omega Y_{1}\left(\beta_{i+1} \omega \bar{r}_{i}\right), \\
\text { for } i & =1 \text { to } n-1 \\
b_{11} & =H_{a}, \quad b_{12}=H_{a} \ln \bar{a}-1 / \bar{a}, \quad b_{2 n 2 n} 1=H_{b}, \quad b_{2 n 2 n}=1, \quad b_{2 i 2 i}=1, \\
b_{2 i 2 i} & =\ln \bar{r}_{i}, \quad b_{2 i 2 i+1}=-1, \quad b_{2 i 2 i+2}=-\ln \bar{r}_{i}, \quad b_{2 i+12 i}=\bar{\lambda}_{i} / \bar{r}_{i}, \\
b_{2 i+12 i+2} & =-\bar{\lambda}_{i+1} / \bar{r}_{i}, \\
\text { for } i & =1 \text { to } n-1 \\
g_{1} & =H_{a}, \quad g_{2 n}=H_{b} \bar{T}_{\mathrm{ext}}
\end{aligned}
$$

This general solution (5) at time $\tau$ is the sum of the permanent solution in logarithm of the radius and of the transient solution written in the form of a series.

\section{MECHANICAL SOLUTION}

\section{General Formulation of the Displacement Field}

At the initial time, let us consider a stress-free state. The thermoelastic orthotropic behavior (6)-(7), with $\alpha$ and $\boldsymbol{L}$, the tensors of thermal expansion coefficients and stiffnesses 
respectively, assumed to be constants, can then be written as:

$$
\begin{aligned}
\left\{\begin{array}{c}
\sigma_{x x} \\
\sigma_{\theta \theta} \\
\sigma_{r r} \\
\tau_{x \theta}
\end{array}\right\}= & {\left[\begin{array}{llll}
L_{x x} & L_{x \theta} & L_{x r} & L_{x s} \\
L_{x \theta} & L_{\theta \theta} & L_{r \theta} & L_{s \theta} \\
L_{x r} & L_{r \theta} & L_{r r} & L_{r s} \\
L_{x s} & L_{s \theta} & L_{r s} & L_{s s}
\end{array}\right] \quad\left\{\begin{array}{l}
\varepsilon_{x x}-\alpha_{x x}\left(T-T_{0}\right) \\
\varepsilon_{\theta \theta}-\alpha_{\theta \theta}\left(T-T_{0}\right) \\
\varepsilon_{r r}-\alpha_{r r}\left(T-T_{0}\right) \\
\gamma_{x \theta}-\alpha_{x \theta}\left(T-T_{0}\right)
\end{array}\right\} } \\
& \left\{\begin{array}{l}
\tau_{r \theta} \\
\tau_{x r}
\end{array}\right\}=\left[\begin{array}{ll}
L_{r \theta r \theta} & L_{\mathrm{r} \theta \mathrm{xr}} \\
L_{x r r \theta} & L_{\mathrm{xrxr}}
\end{array}\right]\left\{\begin{array}{l}
\gamma_{r \theta} \\
\gamma_{x r}
\end{array}\right\}
\end{aligned}
$$

To solve the problem, it is necessary to introduce the classical relationship between displacements and strains, along with the compatibility and equilibrium equations.

Introducing $\alpha_{0}, L_{0},\left(T_{\mathrm{int}}-T_{0}\right)$, we define the following dimensionless variables:

$$
\left\{\begin{array}{l}
\overline{\boldsymbol{\sigma}}=\boldsymbol{\sigma} /\left(L_{0} \alpha_{0}\left(T_{\mathrm{int}}-T_{0}\right)\right), \quad \overline{\boldsymbol{\alpha}}=\boldsymbol{\alpha} / \alpha_{0}, \quad \overline{\boldsymbol{L}}=\boldsymbol{L} / L_{0}, \\
(\bar{w}, \bar{v}, \bar{u})=(w, v, u) /\left(\alpha_{0}\left(T_{\mathrm{int}}-T_{0}\right) b\right), \quad \overline{\boldsymbol{\varepsilon}}=\boldsymbol{\varepsilon} /\left(\alpha_{0}\left(T_{\mathrm{int}}-T_{0}\right)\right) .
\end{array}\right.
$$

The longitudinal and orthoradial displacements $\bar{u}(\bar{x}, \bar{r})$ and $\bar{v}(\bar{x}, \bar{r})$ are then expressed:

$$
\left\{\begin{array}{l}
\bar{u}(\bar{x}, \bar{r})=-\bar{S}_{r \theta x r} \frac{R_{3}}{\bar{r}}+\bar{S}_{x r x r} R_{4} \ln \bar{r}+R_{1} \bar{x}+R_{5}, \\
\bar{v}(\bar{x}, \bar{r})=R_{2} \bar{x} \bar{r}-\frac{\bar{S}_{r \theta r \theta}}{2} \frac{R_{3}}{\bar{r}}-\bar{S}_{r \theta x r} R_{4}+R_{6} \bar{r}, \\
R_{1}, R_{2}, R_{3}, R_{4}, R_{5}, R_{6} \text { are constants and } \boldsymbol{S}=\boldsymbol{L}^{1} .
\end{array}\right.
$$

with $R_{5}$ and $R_{6}$ representing the rigid body displacement and rotation respectively.

Displacements $\bar{u}(\bar{x}, \bar{r})$ and $\bar{v}(\bar{x}, \bar{r})(9)$ are independent of the thermal field. The radial component of the displacement field $\bar{w}$ satisfies the following equation:

$$
\bar{r}^{2} \frac{\partial^{2} \bar{w}}{\partial \bar{r}^{2}}+\bar{r} \frac{\partial \bar{w}}{\partial \bar{r}}-\frac{\bar{L}_{\theta \theta}}{\bar{L}_{r r}} \bar{w}=\frac{\bar{r}\left(\left(\bar{L}_{x \theta}-\bar{L}_{x r}\right) R_{1}+\left(\bar{L}_{s \theta}-2 \bar{L}_{r s}\right) R_{2} \bar{r}+\left(K_{1}-K_{2}\right) \bar{T}+K_{1} \bar{r}(\partial \bar{T} / \partial \bar{r})\right)}{\bar{L}_{r r}}
$$

with,

$$
\begin{aligned}
& K_{1}=\bar{L}_{x r} \bar{\alpha}_{x x}+\bar{L}_{r \theta} \bar{\alpha}_{\theta \theta}+\bar{L}_{r r} \bar{\alpha}_{r r}+\bar{L}_{r s} \bar{\alpha}_{x \theta}, \\
& K_{2}=\bar{L}_{x \theta} \bar{\alpha}_{x x}+\bar{L}_{\theta \theta} \bar{\alpha}_{\theta \theta}+\bar{L}_{r \theta} \bar{\alpha}_{r r}+\bar{L}_{s \theta} \bar{\alpha}_{x \theta} .
\end{aligned}
$$

The general solution of the differential equation (10) is the sum of a solution of the homogeneous equation and of a particular solution obtained by variation of the constant. 


$$
\begin{aligned}
& \bar{w}=R_{7} \bar{r} \sqrt{\bar{L}_{\theta \theta} / \bar{L}_{r r}}+R_{8} \bar{r} \sqrt{ } \bar{L}_{\theta \theta} / \bar{L}_{r r}+\frac{\left(\bar{L}_{x \theta}-\bar{L}_{x r}\right) R_{1} \bar{r}}{\bar{L}_{r r}\left(1-\left(\bar{L}_{\theta \theta} / \bar{L}_{r r}\right)\right)}+\frac{\left(\bar{L}_{s \theta}-2 \bar{L}_{r s}\right) R_{2} \bar{r}^{2}}{\bar{L}_{r r}\left(4-\left(\bar{L}_{\theta \theta} / \bar{L}_{r r}\right)\right)}+\frac{\left(K_{1}-K_{2}\right) A_{i}^{\prime} \bar{r}}{\bar{L}_{r r}\left(1-\bar{L}_{\theta \theta} / \bar{L}_{r r}\right) \Delta_{s}} \\
& +\frac{B_{i}^{\prime}}{\Delta_{s}}\left[\frac{\left(K_{1}-K_{2}\right) \bar{r} \ln \bar{r}+K_{1} \bar{r}}{\bar{L}_{r r}\left(1-\left(\bar{L}_{\theta \theta} / \bar{L}_{r r}\right)\right)}-\frac{2\left(K_{1}-K_{2}\right) \bar{r}}{\bar{L}_{r r}\left(1-\left(\bar{L}_{\theta \theta} / \bar{L}_{r r}\right)\right)^{2}}\right]+\sum_{m=1}^{\infty} \frac{2 \exp \left(-\omega_{m}^{2} \tau\right)}{\omega_{m} \Delta_{u}^{\prime}\left(\omega_{m}\right)} \\
& \times\left[A _ { i } \left\{\frac{\left(K_{1}-K_{2}\right)}{\bar{L}_{r r}} \sum_{k=0}^{\infty} \frac{(-1)^{k}(1 / 2)^{2 k}\left(\beta_{i} \omega_{m}\right)^{2 k}}{(k !)^{2}} \frac{\bar{r}^{(2 k+1)}}{\left((2 k+1)^{2}-\bar{L}_{\theta \theta} / \bar{L}_{r r}\right)}\right.\right. \\
& \left.-\frac{K_{1}}{\bar{L}_{r r}} \sum_{k=0}^{\infty} \frac{(-1)^{k}(1 / 2)^{2 k+1}\left(\beta_{i} \omega_{m}\right)^{2 k+2}}{k !(k+1) !} \frac{\bar{r}^{(2 k+3)}}{\left((2 k+3)^{2}-\bar{L}_{\theta \theta} / \bar{L}_{r r}\right)}\right\}+\frac{B_{i}}{\pi} \\
& \times\left\{\frac { 2 ( K _ { 1 } - K _ { 2 } ) } { \overline { L } _ { r r } } \sum _ { k = 0 } ^ { \infty } \frac { ( - 1 ) ^ { k } ( 1 / 2 ) ^ { 2 k } ( \beta _ { i } \omega _ { m } ) ^ { 2 k } } { ( k ! ) ^ { 2 } } \left[\ln \left(\frac{1}{2} \beta_{i} \omega_{m} \bar{r}\right)-\frac{2(2 k+1)}{\left((2 k+1)^{2}-\bar{L}_{\theta \theta} / \bar{L}_{r r}\right)}\right.\right. \\
& -(k+1)] \frac{\bar{r}^{(2 k+1)}}{\left((2 k+1)^{2}-\bar{L}_{\theta \theta} / \bar{L}_{r r}\right)} \\
& -\frac{\mathrm{K}_{1}}{\bar{L}_{r r}}\left[\sum_{k=0}^{\infty} \frac{(-1)^{k}(1 / 2)^{1+2 k}\left(\beta_{i} \omega_{m}\right)^{2+2 k}}{k !(k+1) !}\left[2 \ln \left(\frac{1}{2} \beta_{i} \omega_{m} \bar{r}\right)-(k+1)-\psi(k+2)\right]\right. \\
& \times \frac{\bar{r}^{(2 k+3)}}{\left((2 k+3)^{2}-\bar{L}_{\theta \theta} / \bar{L}_{r r}\right)}-4 \sum_{k=0}^{\infty} \frac{(-1)^{k}(1 / 2)^{1+2 k}\left(\beta_{i} \omega_{m}\right)^{2+2 k}}{k !(k+1) !}\left(\frac{(2 k+3) \bar{r}^{(2 k+3)}}{\left((2 k+3)^{2}-\bar{L}_{\theta \theta} / \bar{L}_{r r}\right)^{2}}\right) \\
& \left.\left.\left.-2 \frac{\bar{r}}{\left(1-\bar{L}_{\theta \theta} / \bar{L}_{r r}\right)}\right]\right\}\right]
\end{aligned}
$$

with $\psi(k+1)=\sum_{m=1}^{k}(1 / m)+\gamma, \quad \gamma=-0.5772157 \ldots$ (Euler's constant), for, $\bar{L}_{\theta \theta} / \bar{L}_{r r} \neq$ $(2 k+1)^{2}$, and, $\bar{L}_{\theta \theta} / L_{r r} \neq(2 k+3)^{2}$.

\section{DISPLACEMENT FIELD IN THE STEADY-STATE CASE}

The thermal field within each ply $i$ in the steady-state is reduced to:

$$
\bar{T}_{i}(\bar{r})=\frac{1}{\Delta_{s}}\left(A_{i}^{\prime}+B_{i}^{\prime} \ln \bar{r}\right)
$$

Thus the components $(\bar{u}, \bar{v}, \bar{w})$ of the displacement field in the steady state can be written as follows:

$$
\left\{\begin{aligned}
\bar{u}(\bar{x}, \bar{r}) & =-\bar{S}_{r \theta x r} \frac{R_{3}}{\bar{r}}+\bar{S}_{x r x r} R_{4} \ln \bar{r}+R_{1} \bar{x}+R_{5} \\
\bar{v}(\bar{x}, \bar{r}) & =R_{2} \bar{x} \bar{r}-\frac{\bar{S}_{r \theta r \theta}}{2} \frac{R_{3}}{\bar{r}}-\bar{S}_{r \theta x r} R_{4}+R_{6} \bar{r} \\
\bar{w}(\bar{r})= & R_{7} \bar{r} \sqrt{\bar{L}_{\theta \theta} / \bar{L}_{r r}}+R_{8} \bar{r} \sqrt{ } \bar{L}_{\theta \theta} / \bar{L}_{r r}+\frac{\left(\bar{L}_{x \theta}-\bar{L}_{x r}\right) R_{1} \bar{r}}{\bar{L}_{r r}\left(1-\bar{L}_{\theta \theta} / \bar{L}_{r r}\right)}+\frac{\left(\bar{L}_{s \theta}-2 \bar{L}_{r s}\right) R_{2} \bar{r}^{2}}{\bar{L}_{r r}\left(4-\bar{L}_{\theta \theta} / \bar{L}_{r r}\right)} \\
& +\frac{\left(K_{1}-K_{2}\right) A_{i}^{\prime} \bar{r}}{\bar{L}_{r r}\left(1-\bar{L}_{\theta \theta} / \bar{L}_{r r}\right) \Delta_{s}}+\frac{B_{i}^{\prime}}{\Delta_{s}}\left[\frac{\left(K_{1}-K_{2}\right) \bar{r} \ln \bar{r}+K_{1} \bar{r}}{\bar{L}_{r r}\left(1-\bar{L}_{\theta \theta} / \bar{L}_{r r}\right)}-\frac{2\left(K_{1}-K_{2}\right) \bar{r}}{\bar{L}_{r r}\left(1-\bar{L}_{\theta \theta} / \bar{L}_{r r}\right)^{2}}\right]
\end{aligned}\right.
$$


If the temperature is uniform over the thickness of the pipe, we retrieve the expression previously proposed by Ref. [1]:

$$
\bar{w}(\bar{r})=R_{7} \bar{r}^{\sqrt{L_{\theta \theta} / \bar{L}_{r r}}+R_{8} \bar{r} \sqrt{ } \bar{L}_{\theta \theta} / \bar{L}_{r r}}+\frac{\left(\bar{L}_{x \theta}-\bar{L}_{x r}\right) R_{1} \bar{r}}{\bar{L}_{r r}\left(1-\bar{L}_{\theta \theta} / \bar{L}_{r r}\right)}+\frac{\left(\bar{L}_{s \theta}-2 \bar{L}_{r s}\right) R_{2} \bar{r}^{2}}{\bar{L}_{r r}\left(4-\bar{L}_{\theta \theta} / \bar{L}_{r r}\right)}+\frac{\left(K_{1}-K_{2}\right) \bar{r}}{\bar{L}_{r r}\left(1-\bar{L}_{\theta \theta} / \bar{L}_{r r}\right)} \bar{T}
$$

\section{DISPLACEMENT FIELD IN THE CASE OF ISOTROPIC PLIES}

The differential equation (10) for isotropic plies is reduced to:

$$
\bar{r}^{2} \frac{\partial^{2} \bar{w}}{\partial \bar{r}^{2}}+\bar{r} \frac{\partial \bar{w}}{\partial \bar{r}}-\bar{w}=\frac{K_{1} \bar{r}^{2} \partial(\bar{T}) / \partial \bar{r}}{\bar{L}_{r r}}
$$

For the case of isotropic plies the components $\bar{u}$ and $\bar{v}$ become:

$$
\left\{\begin{array}{l}
\bar{u}=\bar{S}_{x r x r} R_{4} \ln (\bar{r})+R_{1} \bar{x}+R_{5} \\
\bar{v}=R_{2} \bar{r} \bar{x}-\frac{\bar{S}_{r \theta r \theta}}{2} \frac{R_{3}}{\bar{r}}+R_{6} \bar{r}
\end{array}\right.
$$

The radial component of the displacement field, solution of Equation (15), is expressed:

$$
\begin{aligned}
\bar{w}(\bar{r})= & R_{7} \bar{r}+\frac{R_{8}}{\bar{r}}+\frac{B_{i}^{\prime}}{2 \Delta_{s}} \frac{K_{1}}{\bar{L}_{r r}} \bar{r} \ln (\bar{r}) \\
& -\sum_{m=1}^{\infty} \frac{2 \exp \left(-\omega_{m}^{2} \tau\right)}{\omega_{m} \Delta_{u}^{\prime}\left(\omega_{m}\right)} \frac{K_{1}}{\bar{L}_{r r}}\left[A_{i} \sum_{k=0}^{\infty} \frac{(-1)^{k}(1 / 2)^{2 k+1}\left(\beta_{i} \omega_{m}\right)^{2 k+2}}{k !(k+1) !} \frac{\bar{r}^{2 k+3}}{\left((2 k+3)^{2}-1\right)}\right. \\
& +\frac{B_{i}}{\pi}\left\{\sum_{k=0}^{\infty} \frac{(-1)^{\mathrm{k}}(1 / 2)^{2 k+1}\left(\beta_{i} \omega_{m}\right)^{2 k+2}}{k !(k+1) !}\left[2 \ln \left(\frac{1}{2} \beta_{i} \omega_{m}\right)-(k+1)-\psi(k+2)\right] \frac{\bar{r}^{(2 k+3)}}{\left((2 k+3)^{2}-1\right)}\right. \\
& \left.\left.+2 \sum_{k=0}^{\infty} \frac{(-1)^{k}(1 / 2)^{2 k+1}\left(\beta_{i} \omega_{m}\right)^{2 k+2}}{k !(k+1) !}\left[\frac{\ln (\bar{r}) \bar{r}^{2 k+3}}{\left((2 k+3)^{2}-1\right)}-\frac{2(2 k+3) \bar{r}^{2 k+3}}{\left((2 k+3)^{2}-1\right)^{2}}\right]-\bar{r} \ln (\bar{r})\right\}\right]
\end{aligned}
$$

We retrieve, in the permanent case, the solution of Ref. [3]:

$$
\bar{w}(\bar{r})=R_{7} \bar{r}+\frac{R_{8}}{\bar{r}}+\frac{B_{i}^{\prime}}{2 \Delta_{s}} \frac{K_{1}}{\bar{L}_{r r}} \bar{r} \ln (\bar{r})
$$

\subsection{Determination of the Constants}

Finally the displacement field in every ply depends on eight constants which are to be determined: $R_{i}$ for $i=1.8$. Those eight constants are derived from the conditions (19)-(22) below:

- rigid body motions restrained

Rigid body motions can be suppressed by setting $R_{5}$ and $R_{6}$ of the inner ply to zero. 
- traction-free conditions at the inner and outer radii

$$
\left\{\begin{array}{l}
\bar{\sigma}_{r r}^{1}(\bar{a})=\bar{\tau}_{r \theta}^{1}(\bar{a})=\bar{\tau}_{x r}^{1}(\bar{a})=0 \\
\bar{\sigma}_{r r}^{n}(1)=\bar{\tau}_{r \theta}^{n}(1)=\bar{\tau}_{x r}^{n}(1)=0
\end{array}\right.
$$

where the superscript refers to the ply number, ply 1 being the inner ply and ply $n$ being the outer ply.

- continuity of the displacement components at each interface between adjacent plies

$$
\left\{\begin{array}{l}
\bar{u}^{i}\left(\bar{x}, \bar{r}_{i}\right)=\bar{u}^{i+1}\left(\bar{x}, \bar{r}_{i}\right) \\
\bar{v}^{i}\left(\bar{x}, \bar{r}_{i}\right)=\bar{v}^{i+1}\left(\bar{x}, \bar{r}_{i}\right) \\
\bar{w}^{i}\left(\bar{r}_{i}\right)=\bar{w}^{i+1}\left(\bar{r}_{i}\right) \\
\text { for } i=1 \text { to }(n-1)
\end{array}\right.
$$

where $r_{i}$ is the location of the interface between plies $i$ and $i+1$.

- continuity of $\bar{\sigma}_{r r}, \bar{\tau}_{r \theta}, \bar{\tau}_{x r}$ at each interface between adjacent plies

$$
\left\{\begin{array}{l}
\bar{\sigma}_{r r}^{i}\left(\bar{r}_{i}\right)=\bar{\sigma}_{r r}^{i+1}\left(\bar{r}_{i}\right) \\
\bar{\tau}_{r \theta}^{i}\left(\bar{r}_{i}\right)=\bar{\tau}_{r \theta}^{i+1}\left(\bar{r}_{i}\right) \\
\bar{\tau}_{x r}^{i}\left(\bar{r}_{i}\right)=\bar{\tau}_{x r}^{i+1}\left(\bar{r}_{i}\right) \\
\text { for } i=1 \text { to }(n-1)
\end{array}\right.
$$

- global force balance of the pipe

$$
\left\{\begin{array}{l}
2 \pi \sum_{i=1}^{n} \int_{\bar{r}_{i 1}}^{\bar{r}_{i}} \bar{\sigma}_{x x}^{i} \bar{r} d \bar{r}=0 \\
2 \pi \sum_{i=1}^{n} \int_{\bar{r}_{i 1}}^{\bar{r}_{i}} \bar{\tau}_{x \theta}^{i} \bar{r}^{2} d \bar{r}=0
\end{array}\right.
$$

The integrals enforce the zero axial force and torsion conditions. Both conditions must be achieved because no loading is being applied to the pipe.

\section{EXAMPLES}

We consider a thick pipe of infinite length composed of five orthotropic unidirectional carbon/epoxy plies (T300/5208) oriented alternatively at +55 and -55 degrees versus the longitudinal axis. The pipe is thermally homogeneous since the ply thermal properties do not vary in the radial direction, and the stress is applied here on the mechanical heterogeneity. The objective is to calculate the in-service stress state, due to the time varying temperature, which should be added to the residual stress state due to the pipe processing. 
Table 1. Thermal properties.

\begin{tabular}{lccccr}
\hline Material & $\lambda(\mathrm{W} / \mathrm{m} \mathrm{K})$ & $\rho\left(\mathbf{k g} / \mathrm{m}^{3}\right)$ & $\mathrm{c}(\mathrm{J} / \mathbf{k g ~ K})$ & $\boldsymbol{h}_{\mathrm{a}}\left(\mathrm{m}^{\mathbf{1}}\right)$ & $\boldsymbol{h}_{\mathrm{b}}\left(\mathrm{m}^{\mathbf{1}}\right)$ \\
\hline T300/5208 & 0.7 & 1590 & 857 & 40 & 69 \\
\hline
\end{tabular}

Table 2. Mechanical properties in the reference frame linked to the fibers $(1,2,3)$.

\begin{tabular}{lccccccc}
\hline Material & $E_{1}(\mathrm{GPa})$ & $E_{2}, E_{3}(\mathrm{GPa})$ & $v_{12}, v_{13}$ & $v_{23}$ & $G_{12}(\mathrm{GPa})$ & $\alpha_{1}\left(K^{-1}\right)$ & $\alpha_{2}, \alpha_{3}\left(K^{-1}\right)$ \\
\hline T300/5208 & 181 & 10.3 & 0.28 & 0.43 & 7.17 & $0.02 \times 10^{6}$ & $22.5 \times 10^{6}$ \\
\hline
\end{tabular}

Table 3. T300/5208 strengths (Tsai, 1987).

\begin{tabular}{lcccr}
\hline Strengths (MPa) & $X, X^{\prime}$ & $Y, Z$ & $Y^{\prime}, Z^{\prime}$ & $S$ \\
\hline T300/5208 & 1500 & 40 & 246 & 68 \\
\hline
\end{tabular}

The thermal properties [7] and the mechanical properties [8] of the composite T300/5208 are presented in Tables 1 and 2.

The Tsai $\mathrm{Wu}$ strength criterion allows us to estimate the internal stresses versus the ply strength. In Table 3 are reported the tensile strengths in the longitudinal, normal and transverse directions denoted respectively $X, Y, Z$. The corresponding strengths in compression are $X^{\prime}, Y^{\prime}, Z^{\prime}$ and $S$ stands for the plane shear strength. These strengths are assumed to be independent of the temperature.

$R$, the strength factor derived from the Tsai $\mathrm{Wu}$ strength criterion, stands for the ratio between the ultimate and the applied stress. Therefore, failure occurs when $R$ is less than or equal to 1 .

\section{Heating Process}

The inner and outer radii of the pipe are 100 and $300 \mathrm{~mm}$ respectively. The heating process considered here is determined by the three following temperatures, respectively the reference temperature and the inner and outer temperatures: $T_{0}=293 \mathrm{~K}, T_{\mathrm{int}}=313 \mathrm{~K}$ and $T_{\text {ext }}=413 \mathrm{~K}$.

The time-dependent temperature profiles resulting from the application of the temperatures above are shown in Figure 2. At the beginning of the heating process important thermal gradients take place near the outer surface. The logarithmic permanent solution is reached after $6 \times 10^{4} \mathrm{~s}$.

Normal in-plane stresses in the fiber direction (Figure 3) can reach $100 \mathrm{MPa}$ in tension and compression in the permanent case, corresponding to $7 \%$ only of the longitudinal strength. It is interesting to note that the maximum value does not necessary occur in the surface ply.

The normal in-plane stress in the transverse direction to the fibers remains negative, except during the very initial stages (Figure 4). This means that probably no damage will 


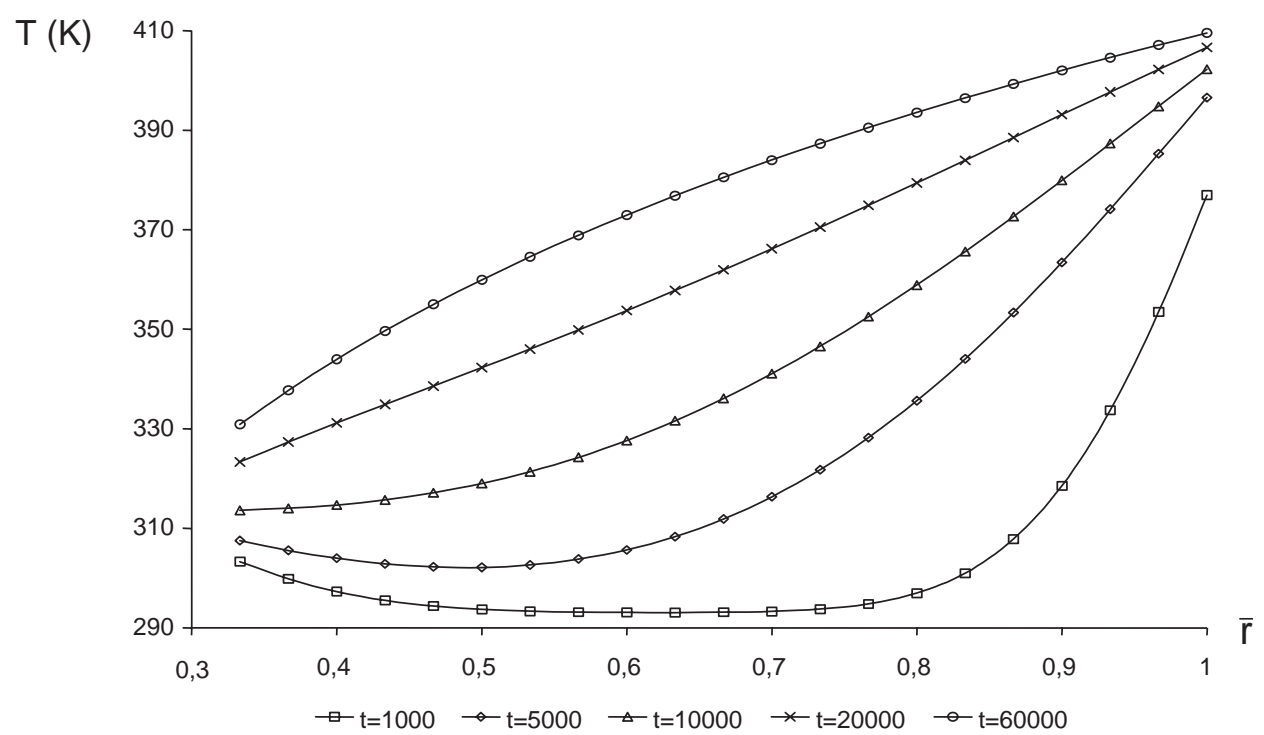

Figure 2. Profiles of temperatures at different times during the heating process.

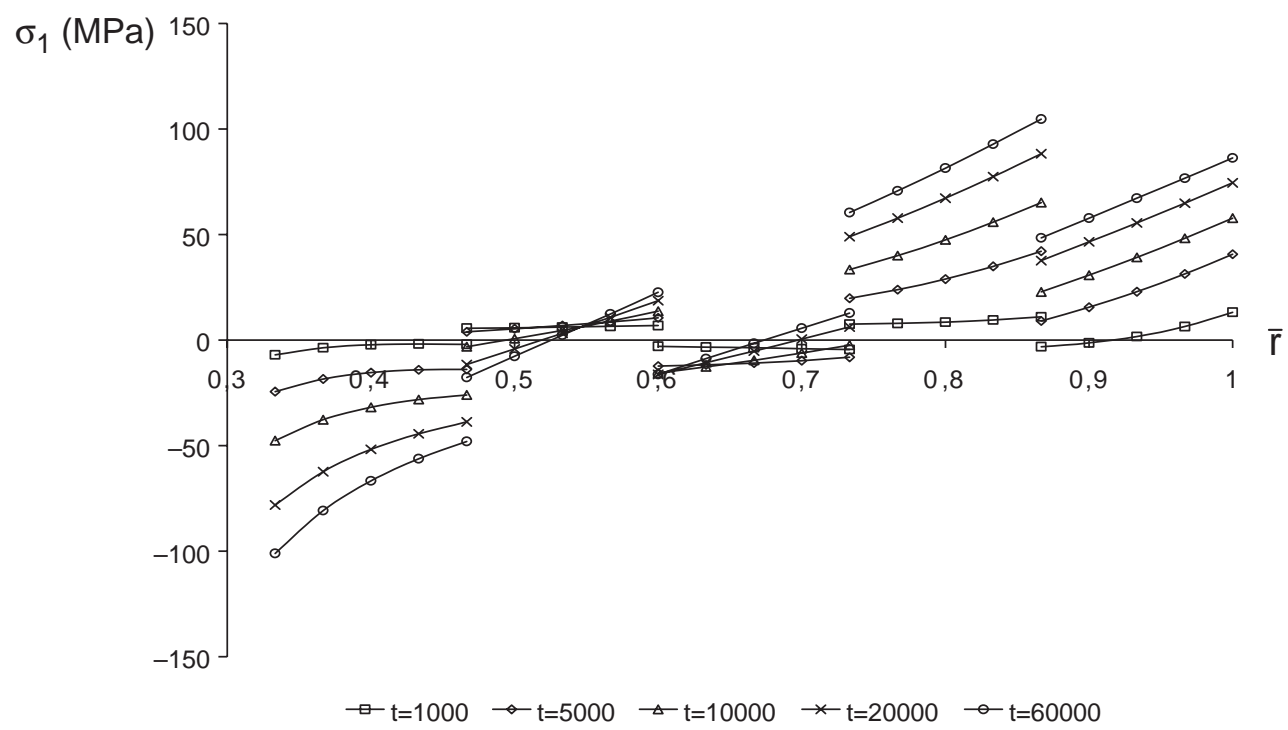

Figure 3. Normal ply stress in the fiber direction during the heating process.

occur due to that stress which is most critical within unidirectional plies. The stress value at the outer surface is more or less constant and controlled by the outer temperature. Finally, the strong temperature gradients close to the pipe surface do not induce any critical transverse overstress. The calculation of the radial stress (Figure 5) proves that the pipe wall is in radial compression, therefore delamination will not occur due to the heating loading. The continuity of the radial stress simply results from the interface 


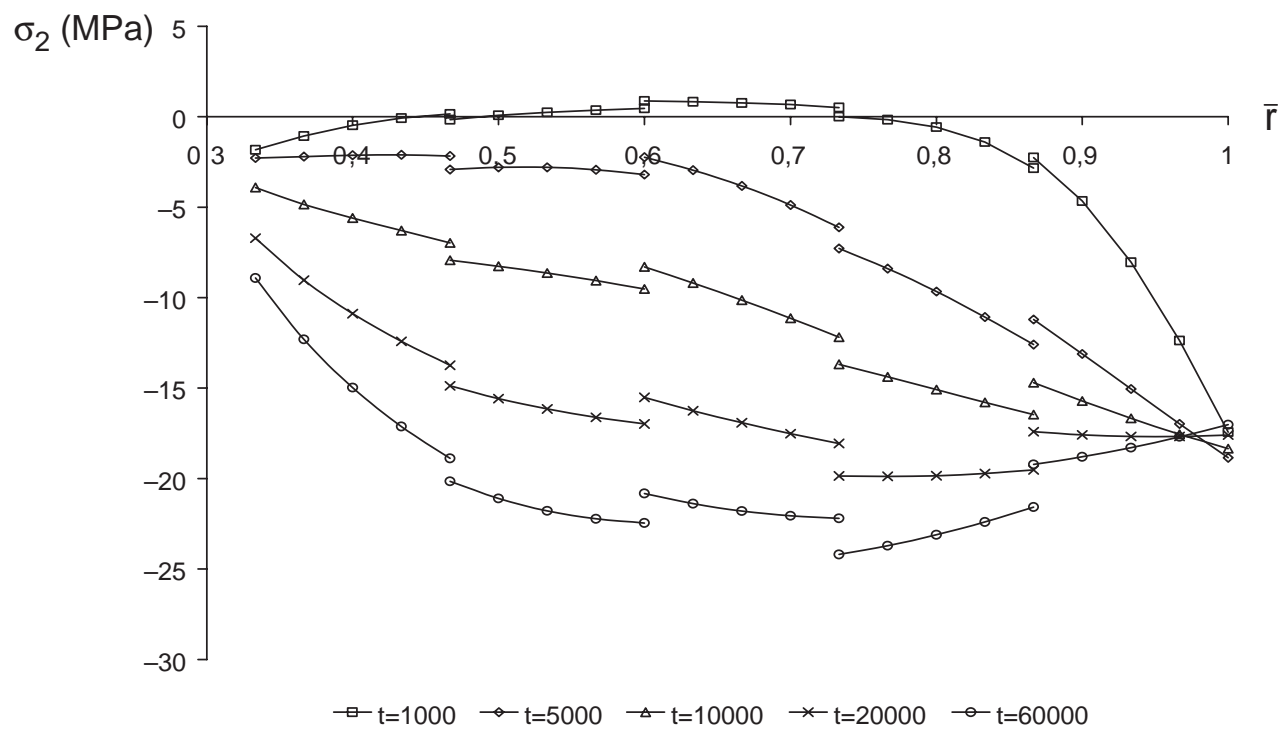

Figure 4. Normal ply stress in the transverse direction to the fibers during the heating process.

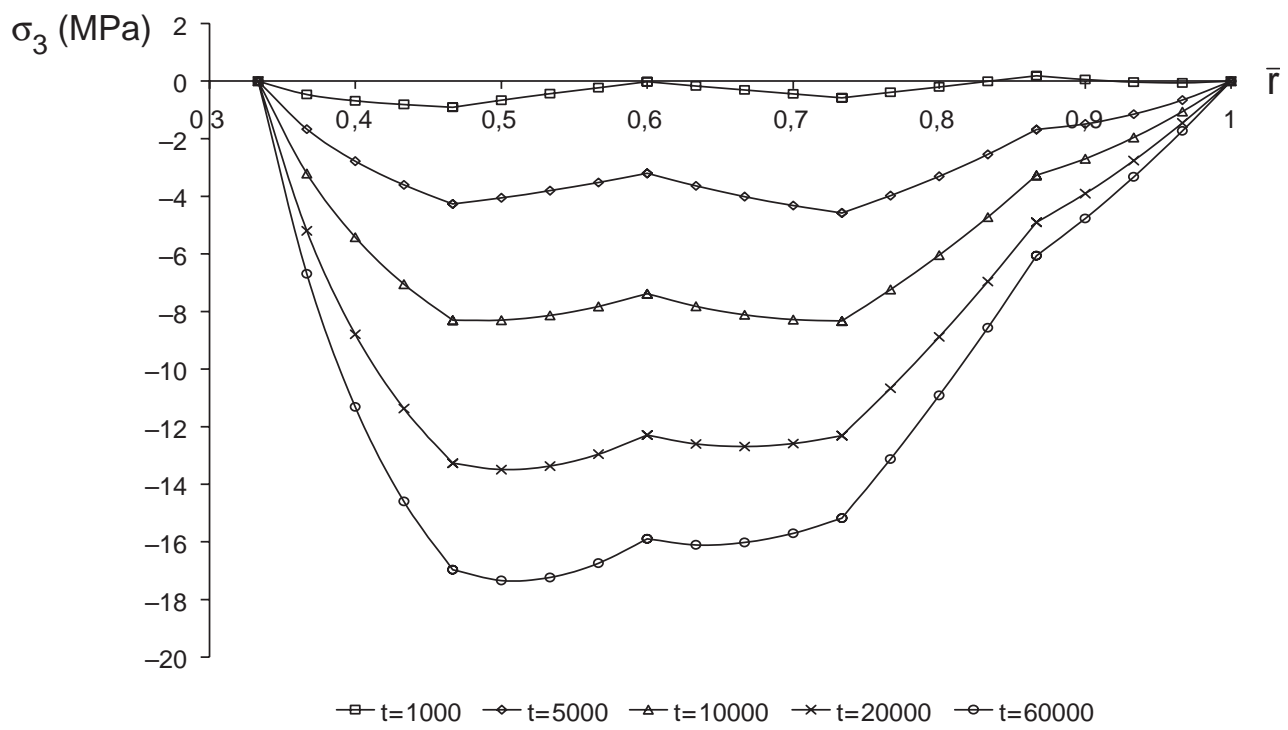

Figure 5. Radial stress during the heating process.

equilibrium. The intralaminar shear stress (Figure 6) is characteristic of the ply anisotropy and stacking sequence. It reaches values close to $10 \mathrm{MPa}$, corresponding to $15 \%$ of the shear strength. This value is significant and should be taken into account when designing the structure.

The strength factor decreases versus the temperature (Figure 7) showing that the permanent state seems to be more critical than the transient states in spate of the 


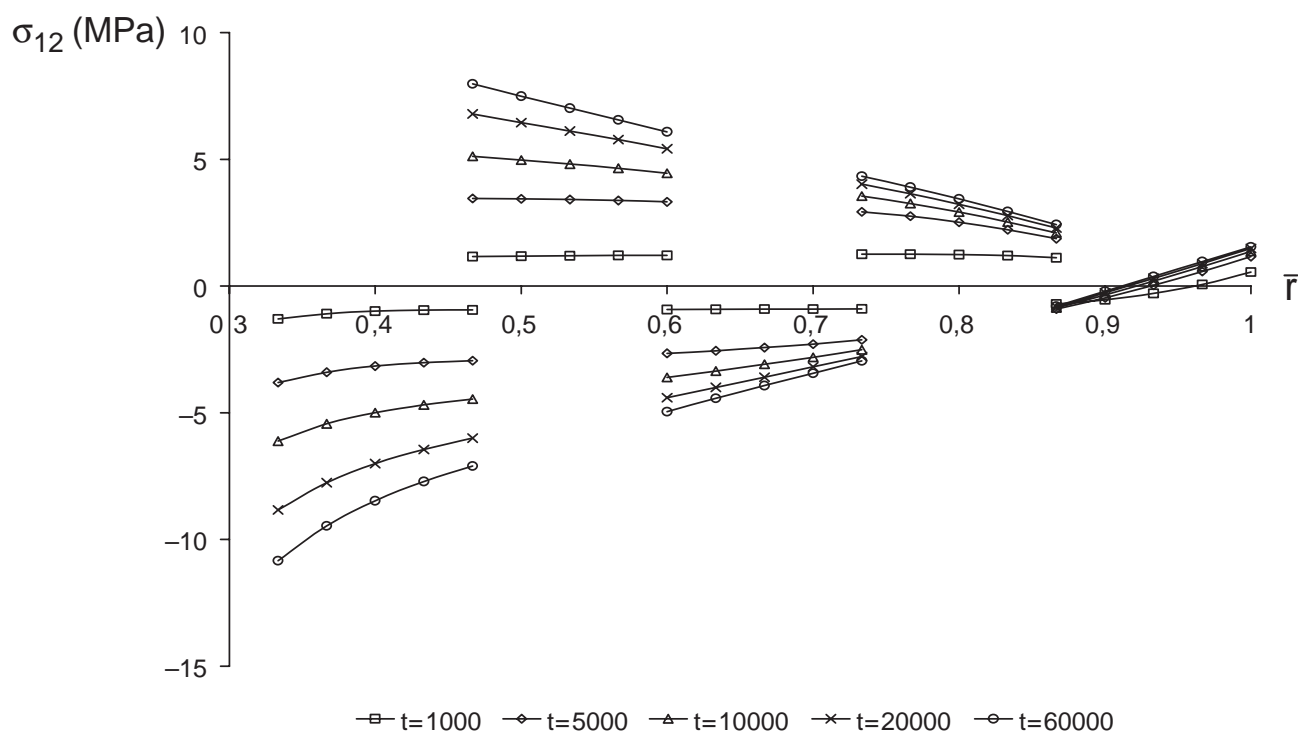

Figure 6. Shear stress during the heating process.

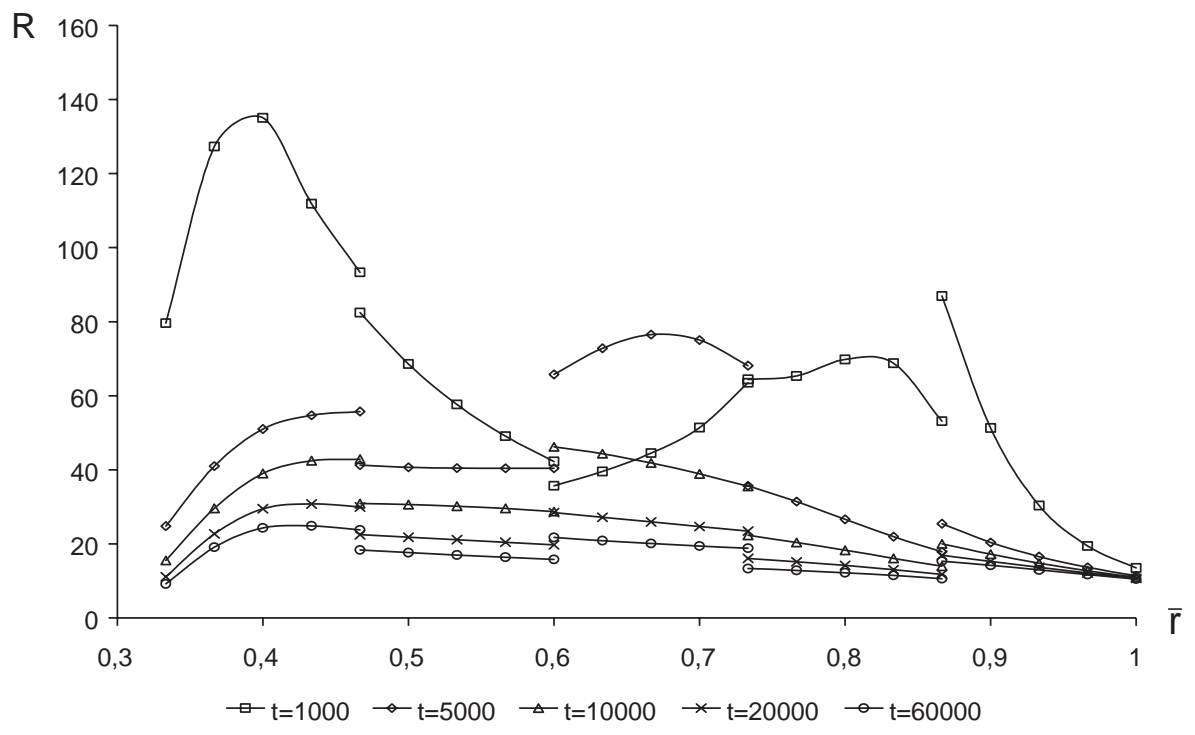

Figure 7. Thermal strength factor during the heating process.

temperature gradients. This coefficient provides a global measure of the effects of the stress state; in that case values over 10 mean that the permanent thermal state is not presenting any risk. This result is induced by the compression state in the radial and transverse directions. The transient analysis emphasizes the existence of similar strength factors in the initial stages and for the permanent case on the outer surface. 


\section{Cooling Process}

The inner and outer radii of the pipe are still 100 and $300 \mathrm{~mm}$ respectively. The cooling process is defined by the following temperatures: $T_{0}=293 \mathrm{~K}, T_{\text {int }}=233 \mathrm{~K}$ and $T_{\text {ext }}=233 \mathrm{~K}$.

The temperature field due to the cooling (Figure 8) shows strong spatial gradients at the beginning of the process. On the inner and outer surfaces the temperature reaches 260 and $250 \mathrm{~K}$ respectively, while within the pipe wall the initial temperature of $293 \mathrm{~K}$ still prevails. Even if the temperature on the surfaces decreases, the fact that the cooling diffuses through the whole cylinder finally reduces the thermal gradients. Eventually, a permanent uniform state is reached due to identical boundary conditions.

The maximum normal stress in the fiber direction (Figure 9) is quite similar to that of the heating process but the gradient is opposite. In the first time, the thermal gradients have a significant effect on the normal in-plane stress transverse to the fibers (Figure 10). Compared to the heating process, the cooling induces positive stress gradients both for the radial and in-plane normal stresses (Figures 10 and 11). The normal in-plane stress transverse to the fibers reaches positive values which are about $50 \%$ of the transverse strength (Table 3). There is no significant change in the shear stress pattern except the sign of the gradient (Figure 12).

Finally, as one could have forecast, the strength factors (Figure 13) are smaller than in the heating case. In the permanent case for instance, the factor is comprised between 1 and 2 within the cylinder. Compared to the heating process, the strength factor is reduced due to the tensile stresses which occurs, since the difference between the curing and the operating temperatures is increasing.

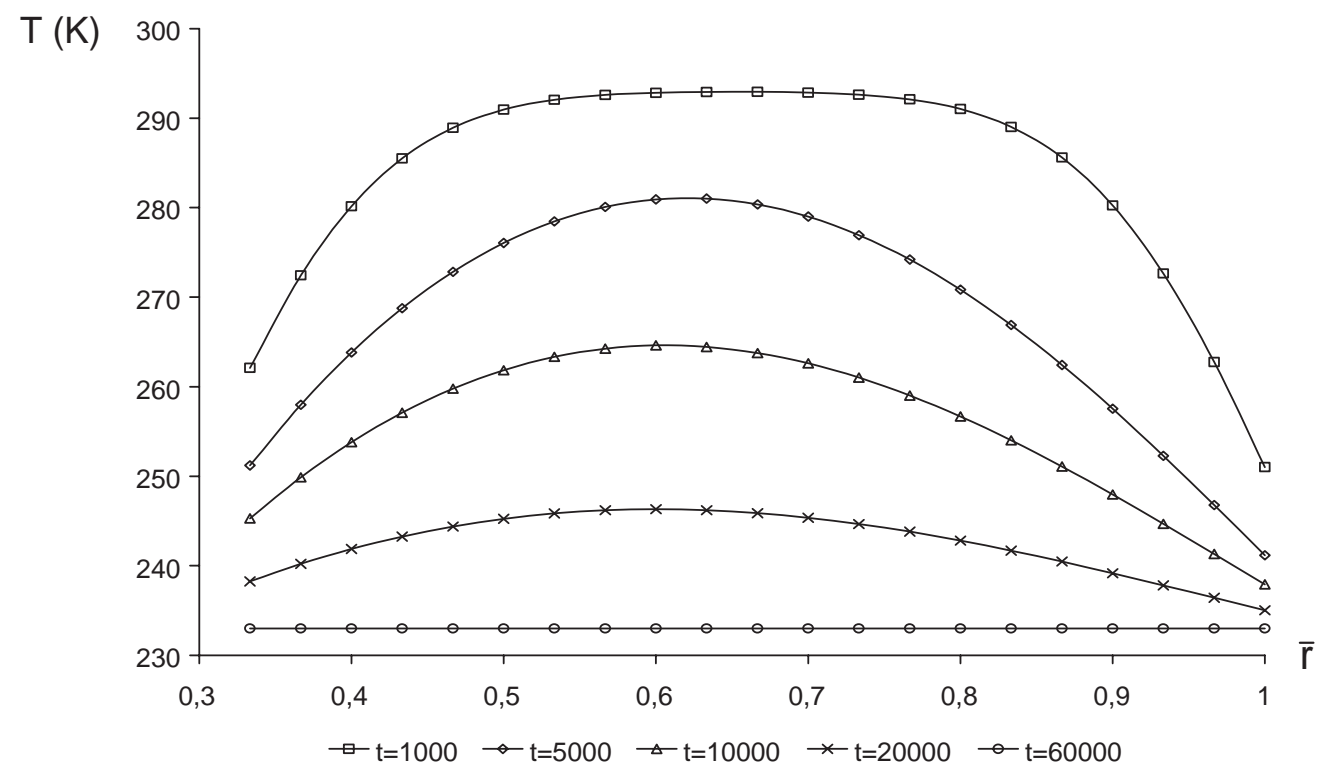

Figure 8. Profiles of temperatures at different times during the cooling process. 


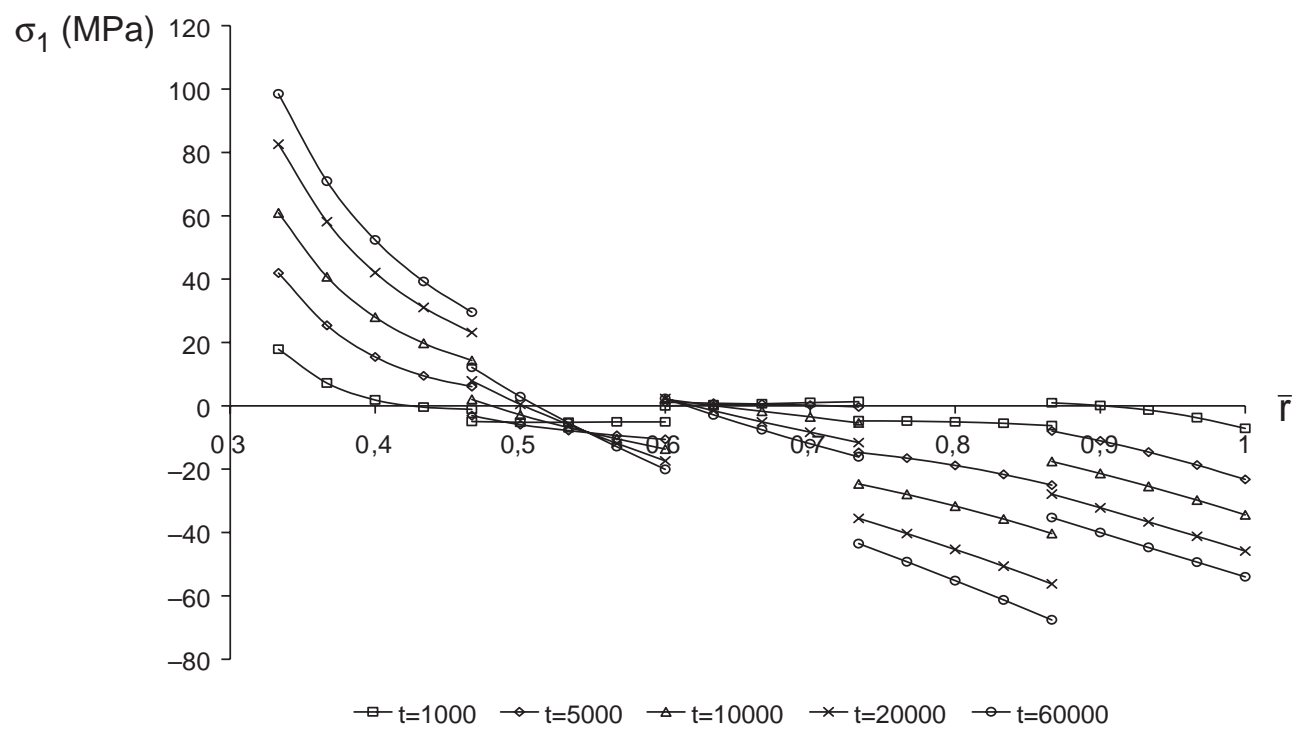

Figure 9. Normal ply stress in the fiber direction during the cooling process.

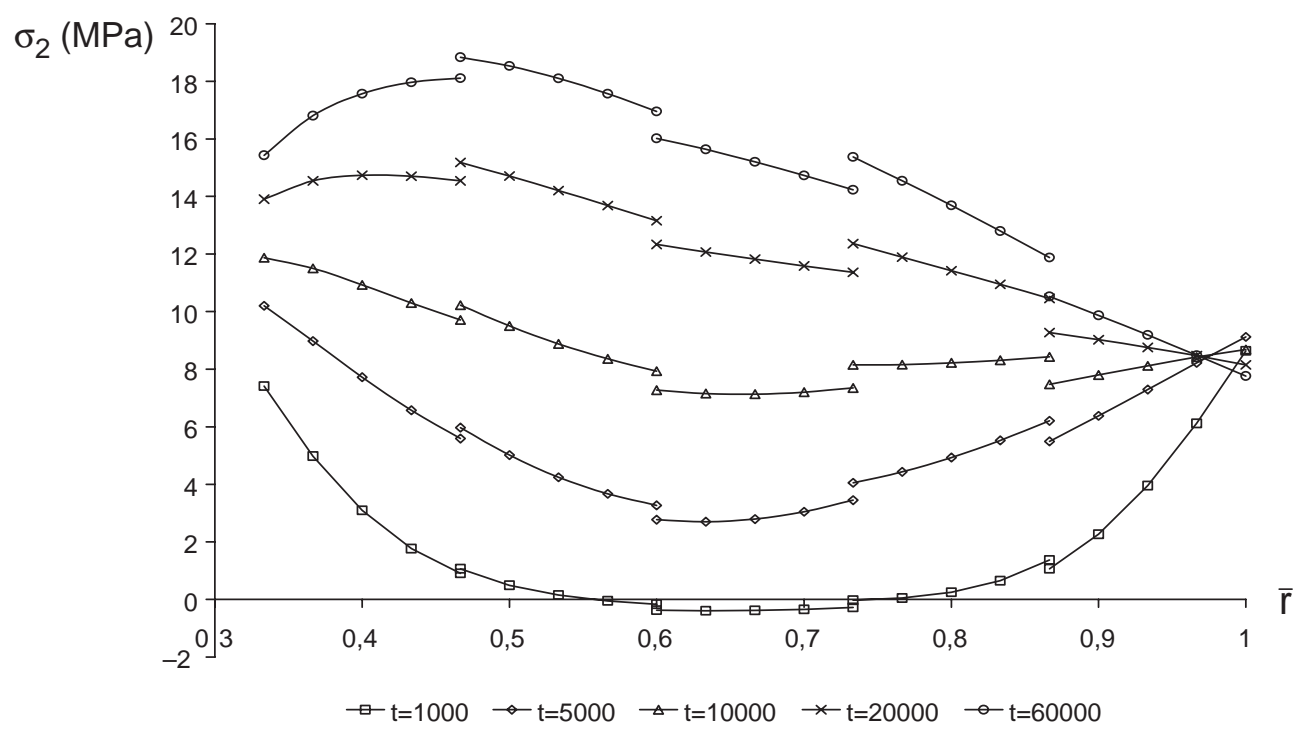

Figure 10. Normal ply stress in the transverse direction to the fibers during the cooling process.

\section{Effect of Wall Thickness}

In this section, special attention is paid to the particular effect of the wall thickness on the internal stress development. For the composite pipes considered, which are composed of five orthotropic unidirectional carbon/epoxy plies (T300/5208) oriented alternatively at +55 and -55 degrees, the outer radius is $300 \mathrm{~mm}$ and the inner radius $a$ take the values of 


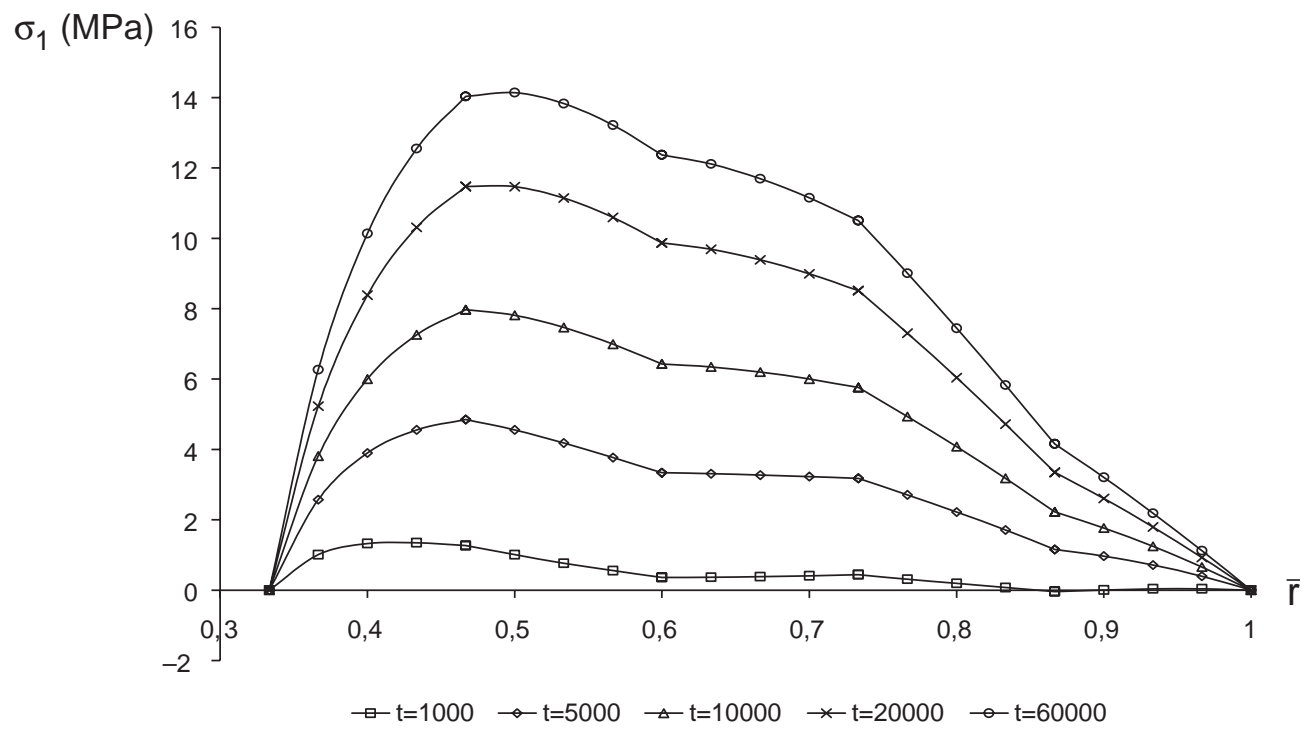

Figure 11. Radial stress during the cooling process.

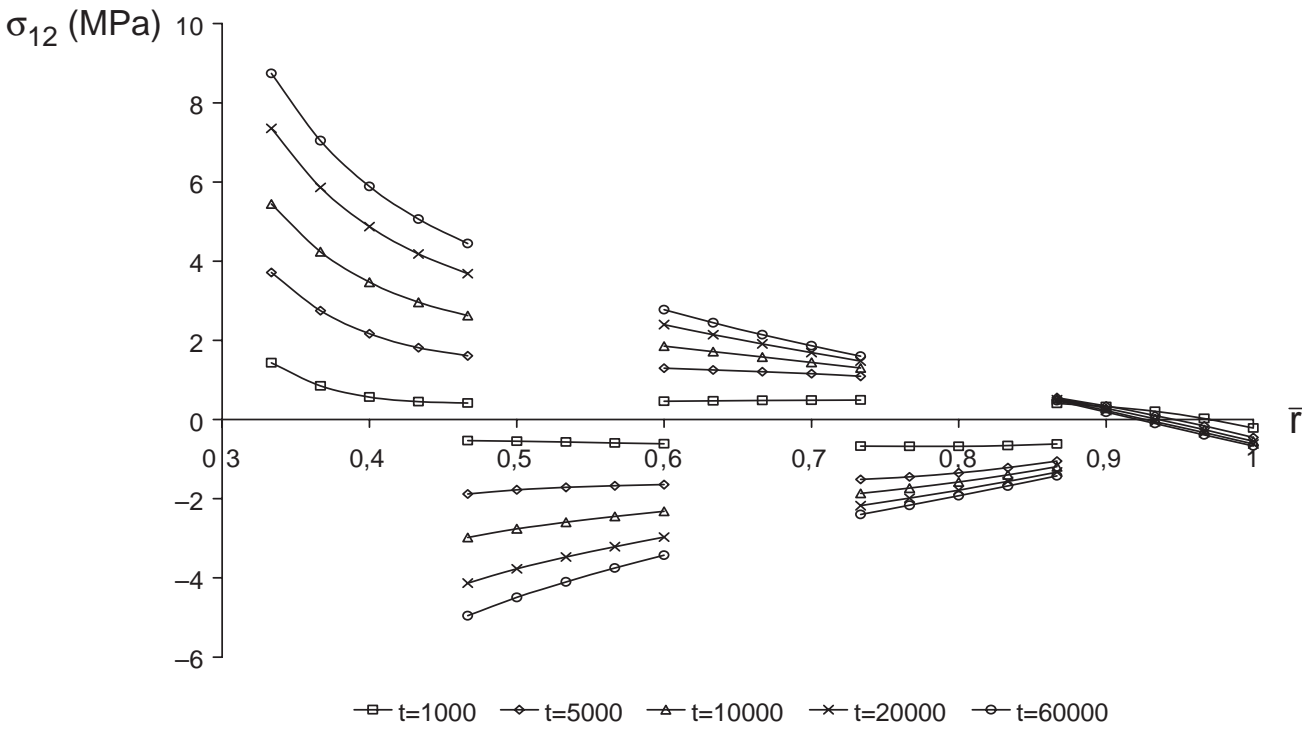

Figure 12. Shear stress during the cooling process.

200, 220, 240, 260 or $280 \mathrm{~mm}$. The boundary conditions are the same as those used for the cooling process: $T_{0}=293 \mathrm{~K}, T_{\text {int }}=233 \mathrm{~K}$ and $T_{\text {ext }}=233 \mathrm{~K}$. When the uniform permanent temperature fields hold in the composite pipes, the corresponding internal stresses and strength factors are studied.

For the stresses in the fiber direction (Figure 14) and in the direction transverse to the fibers (Figure 15), the thickness decrease involves a reduction of the stress gradients. 


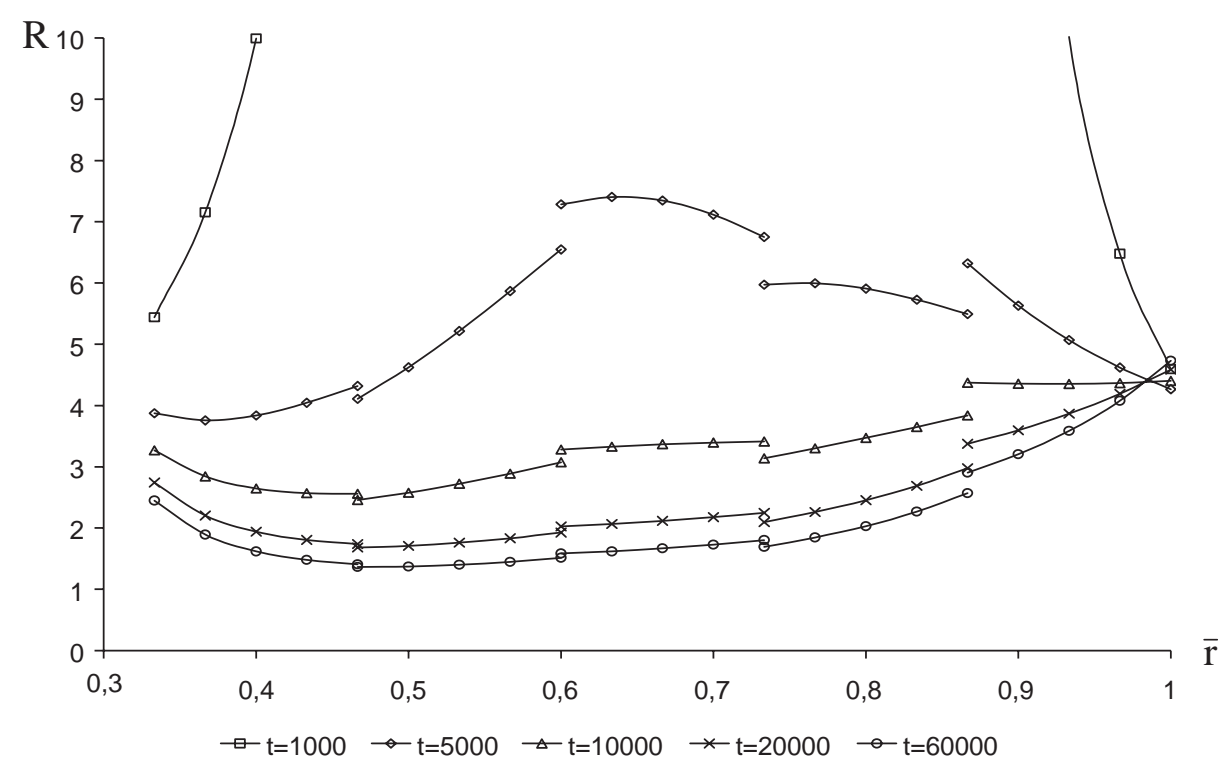

Figure 13. Thermal strength factor during the cooling process.

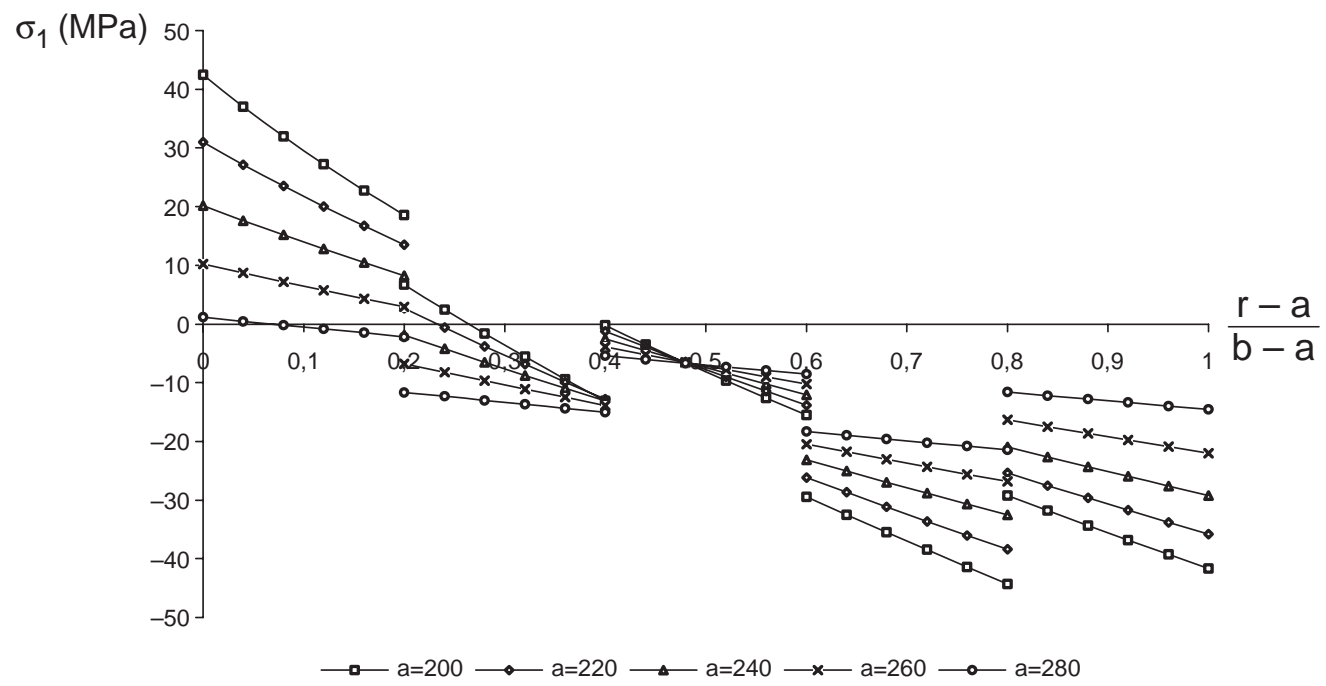

Figure 14. Normal ply stress in the fiber direction.

The radial stresses are growing functions of the pipe thickness (Figure 16). The intralaminar shear stress (Figure 17) tends towards constant values within unidirectional plies when the thickness decreases. Reducing the thickness leads to an increase of the strength factor except on the external ply and reduces the internal stresses (Figure 18). This result illustrates the significant influence the wall thickness has on the internal stress development. For the thin composite pipe with an internal radius of $280 \mathrm{~mm}$, we obtain 


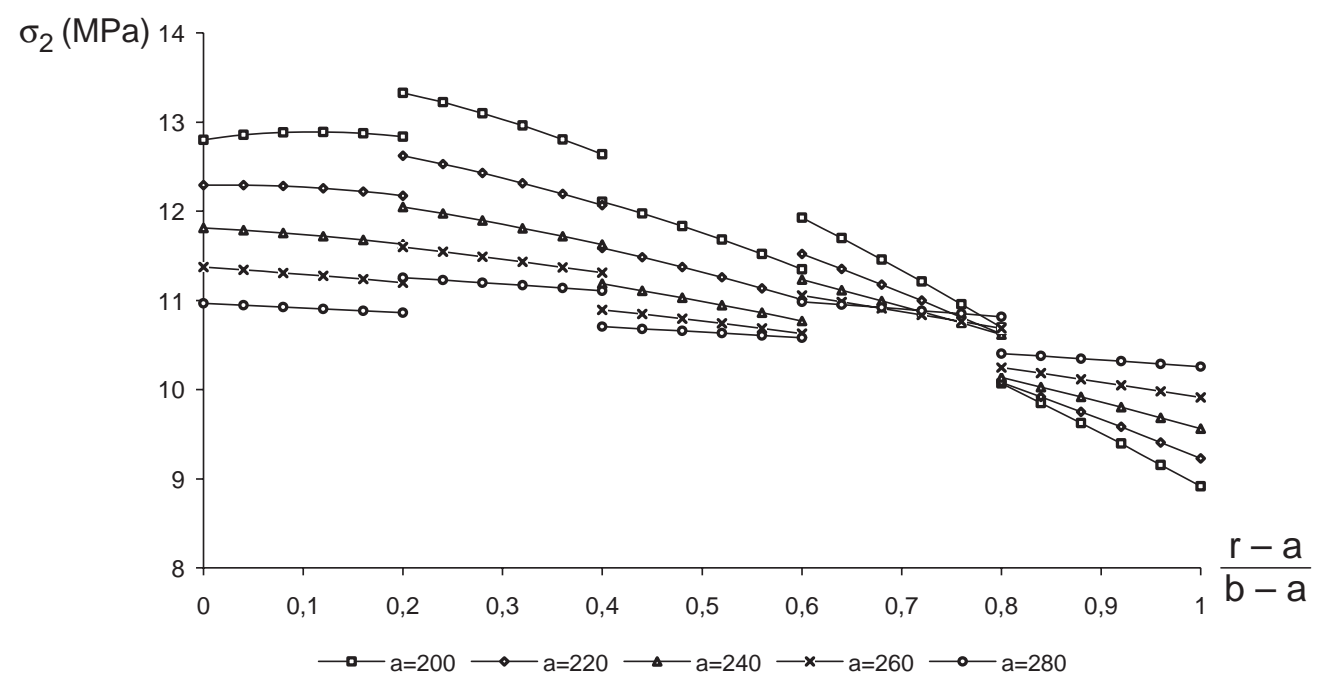

Figure 15. Normal ply stress in the transverse direction to the fibers.

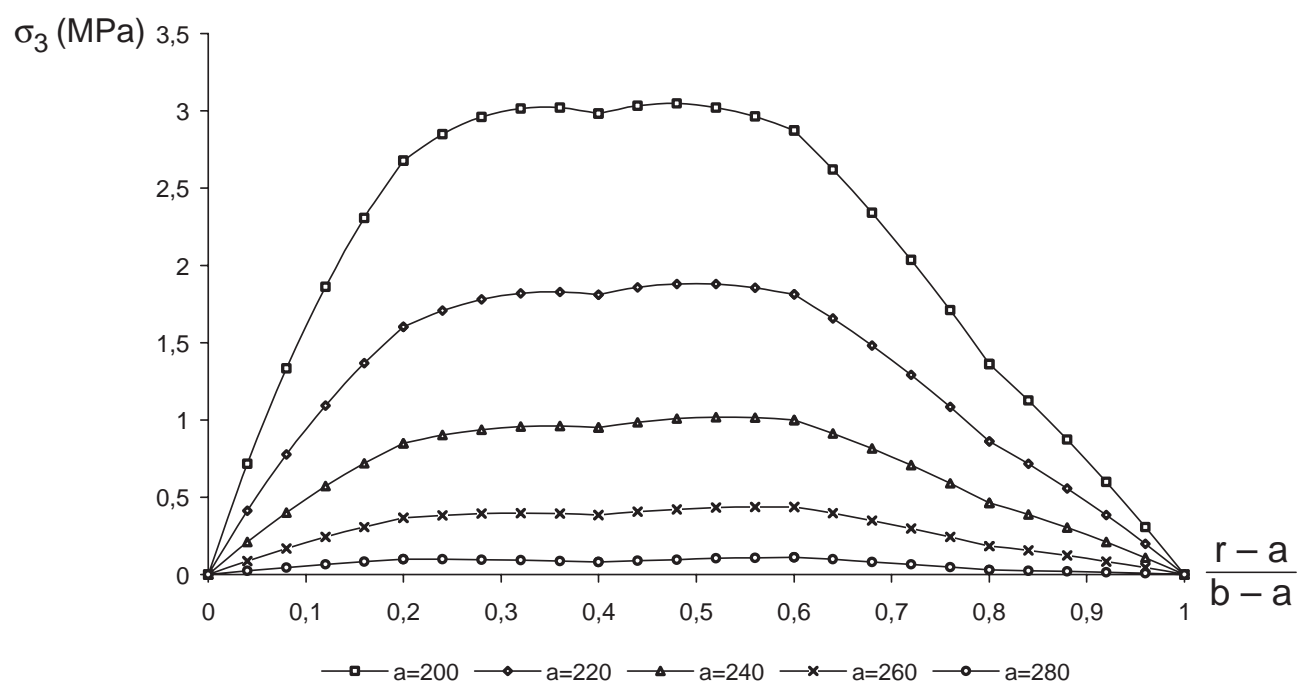

Figure 16. Radial stress.

constant ply stresses and a negligible radial stress. Such stress profiles are similar to what would be predicted by the classical laminated plate theory.

\section{CONCLUSION}

The paper presents a reference analytical solution to compute the thermoelastic stresses in tubular laminated structures. This solution makes it possible to analyze the influence of a transient thermal field on thick, laminated, anisotropic pipes and therefore to design components accounting for internal thermoelastic stresses. 


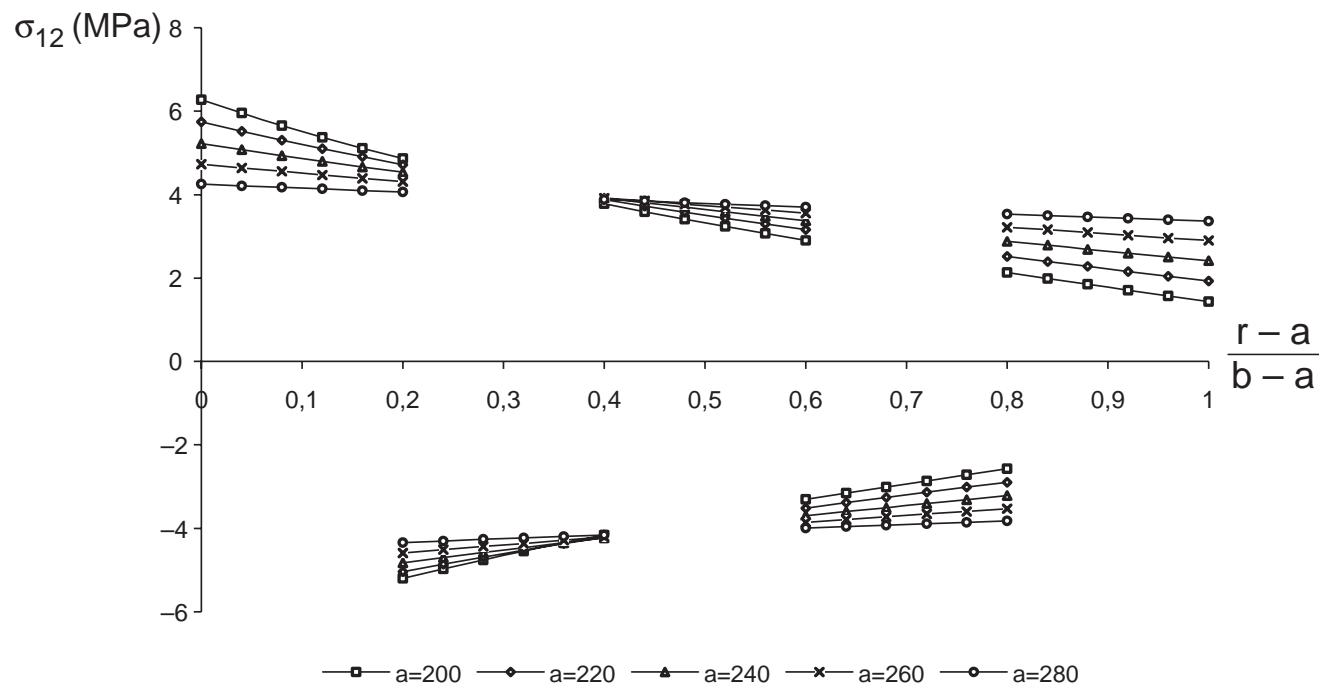

Figure 17. Shear stress.

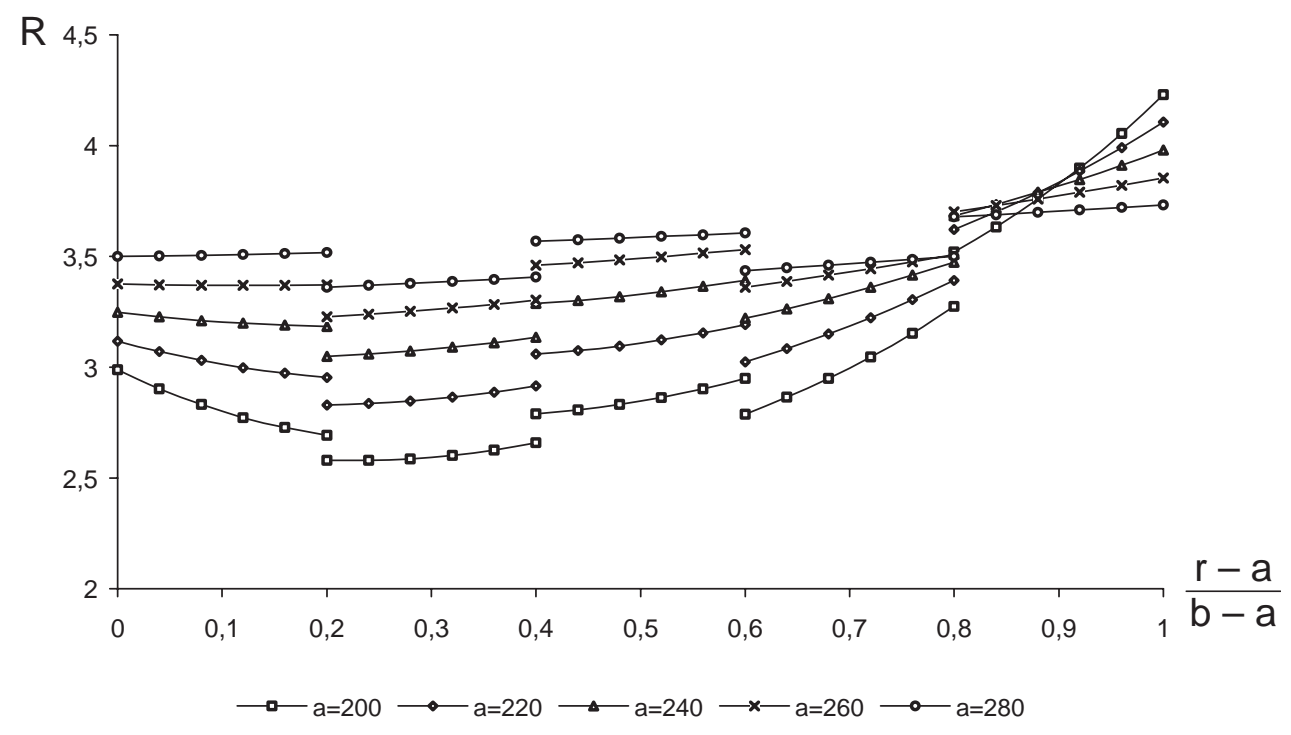

Figure 18. Thermal strength factor.

In this article two thermal loading cases are studied: a heating process and a cooling process. It was especially observed that the cooling process, involving tensile stresses, is clearly more dangerous than the heating process, involving compressive stresses only.

Furthermore, this type of solution can be useful to validate or control special FE approaches since it does not introduce any restrictive assumptions on the thickness nor the stacking sequence of the laminate. The solution can be extended to hygrothermal time dependent cases also. 


\section{REFERENCES}

1. Hyer, M.W. and Rousseau, C.Q. (1987). Thermally Induced Stresses and Strains in Angle Ply Composites Pipes, Journal of Composite Materials, 21: 454480.

2. Shin, E.S. and Sekine, H. (1999). Residual Stress Minimisation to Prevent Process Induced Damage in Thick Walled CFRP Pipes, In: Proceedings of the Twelfth International Conference on Composite Materials, ICCM12, Paris.

3. Timoschenko, S. and Goodier, J.N. (1962). Theory of Elasticity, McGraw Hill, New York.

4. Ootao, Y., Tanigawa, Y. and Fukuda, T. (1991). Axisymmetric Transient Thermal Stress Analysis of a Multilayered Composite Hollow Cylinder, Journal of Thermal Stresses, 14: 201213.

5. Tanigawa, Y., Oka, N., Akai, T. and Kawamura, R. (1997). One Dimensional Transient Thermal Stress Problem for Non Homogeneous Hollow Circular Cylinder and its Optimization of Material Composition for Thermal Stress Relaxation, JSME International Journal, 40: 117127.

6. Carslaw H.S. and Jaeger, J.C. (1974). Conduction of Heat in Solids, Clarendon Press, Oxford.

7. Tzeng, J.T. and Loos, A.C. (1993). A Cure Analysis for Axisymmetric Composites, Composite Manufacturing, 4: 4351.

8. Tsai, S.W. (1987). Composite Design, 3rd edn, Think Composites, Dayton, Ohio. 